DOI: 10.20472/IAC.2017.032.032

\title{
CATHERINE NAMOME
}

University of Cape Town, South Africa

\section{CORNE VAN WALBEEK}

University of Cape Town, South Africa

\section{EFFECTS OF PRICES AND YIELDS ON THE CHOICE OF FARMING TOBACCO, RESULTS FROM UGANDA}

\begin{abstract}
:
Objective:

Tobacco farming is important amongst smallholder farm households, and controversial within policy circles and tobacco control lobbyists. There is little knowledge about why farmers farm tobacco. We examined, cross-sectionally, why farmers grow tobacco and tested whether price and yield stimuli of tobacco and non-tobacco crops would influence the choice of farming tobacco.

Methods:

A cross-sectional based survey with a sample of 126 farm households (mean farm acreage 5 ) in the West Nile sub-region of Uganda were surveyed in 2014. We assessed the structure of their land system, access to finance, input use, production and farm expenditure of tobacco and non-tobacco crops. Regression analyses tested whether price and crop yield ratios, controlling for resources were related to the choice of growing tobacco.

Results:

Tobacco farmers are less likely to farm tobacco leaf if there is an increase in the price ratio of coffee to tobacco, $-0.800 p<0.0001$, although the effect of the yield ratio of coffee to tobacco was small and not significant. Similarly, the chances of farming tobacco leaf were low as the yield ratio of cassava to tobacco increased, $-0.081 p<0.05$. It is evident that uptake of tobacco farming is not strongly influenced by household factors especially, household size, gender of the head of the household, although age and education level of the head of households did have a slight influence on the decision to grow tobacco.

Conclusion:

Data from this study indicate that tobacco farmers are price and yield sensitive, and this result together with other findings confirm the view that tobacco farmers can switch to other crops if they are able to obtain a higher price for their alternative crops.
\end{abstract}

\section{Keywords:}

Tobacco, Prices, Yields

JEL Classification: D21, A10, A19 